\title{
Inhibition of mouse brown adipocyte differentiation by second-generation antipsychotics
}

\author{
Jee-Eun Oh ${ }^{1}$, Yoon Mi Cho', Su-Nam Kwak ${ }^{1}$, \\ Jae-Hyun Kim ${ }^{2}$, Kyung Won Lee ${ }^{1}$, Hyosan Jung', \\ Seong-Whan Jeong ${ }^{1}$ and Oh-Joo Kwon ${ }^{1,3}$ \\ ${ }^{1}$ Department of Biochemistry \\ College of Medicine \\ The Catholic University of Korea \\ Seoul 137-701, Korea \\ ${ }^{2}$ Department of Psychiatry \\ Wonkwang University School of Medicine \\ Sanbon Hospital \\ Gunpo 435-040, Korea \\ ${ }^{3}$ Corresponding author: Tel, 82-2-2258-7292; \\ Fax, 82-2-596-4435; E-mail, ojkwon@ catholic.ac.kr \\ http://dx.doi.org/10.3858/emm.2012.44.9.062
}

Accepted 13 June 2012

Available Online 19 July 2012

Abbreviations: ACC, acetyl-CoA carboxylase; aP2, adipocyte protein 2; BAT, brown adipose tissue; CD36, cluster of differentiation 36; C/EBP $\beta$, CCAAT-enhancer-binding protein beta; Cidea, cell death-inducing DFFA-like effector a; CYP, cytochrome P450; FAS, fatty acid synthase; GLUT4, glucose transporter 4; PGC-1 $\alpha$, peroxisome proliferator-activated receptor gamma coactivator-1 alpha; PKC- $\beta$, protein kinase C-beta; PPAR $\gamma$, peroxisome proliferatoractivated receptor gamma; PRDM16, PR domain containing 16; qRT-PCR, quantitative real-time polymerase chain reaction; SCD1, stearyl-CoA desaturase 1; SGA, second-generation antipsychotics; TRR, therapeutic reference ranges; UCP-1, uncoupling protein-1

\begin{abstract}
Brown adipose tissue is specialized to burn lipids for thermogenesis and energy expenditure. Secondgeneration antipsychotics (SGA) are the most commonly used drugs for schizophrenia with several advantages over first-line drugs, however, it can cause clinically-significant weight gain. To reveal the involvement of brown adipocytes in SGA-induced weight gain, we compared the effect of clozapine, quetiapine, and ziprasidone, SGA with different propensities to induce weight gain, on the differentiation and the expression of brown fat-specific markers,
\end{abstract}

lipogenic genes and adipokines in a mouse brown preadipocyte cell line. On Oil Red-O staining, the differentiation was inhibited almost completely by clozapine $(40 \mu \mathrm{M})$ and partially by quetiapine $(30 \mu \mathrm{M})$. Clozapine significantly down-regulated the brown adipogenesis markers PRDM16, C/EBP $\beta, P P A R \gamma 2$, UCP-1, PGC-1 $\alpha$, and Cidea in dose- and time-dependent manners, whereas quetiapine suppressed PRDM16, $P P A R \gamma 2$, and UCP-1 much weakly than clozapine. Clozapine also significantly inhibited the mRNA expressions of lipogenic genes ACC, SCD1, GLUT4, $a P 2$, and $C D 36$ as well as adipokines such as resistin, leptin, and adiponectin. In contrast, quetiapine suppressed only resistin and leptin but not those of lipogenic genes and adiponectin. Ziprasidone $(10 \mu \mathrm{M})$ did not alter the differentiation as well as the gene expression patterns. Our results suggest for the first time that the inhibition of brown adipogenesis may be a possible mechanism to explain weight gain induced by clozapine and quetiapine.

Keywords: adipocytes, brown; adipogenesis; antipsychotic agents; PPAR gamma; PRDM16 protein, human

\section{Introduction}

Second-generation antipsychotics (SGA) are the most common drugs used for treatment of schizophrenia and have a reduced risk of extrapyramidal symptoms compared to first-generation antipsychotics. However, most SGA are linked to weight gain, impaired glucose tolerance and lipid abnormalities, resulting in the development of various metabolic disorders. A high prevalence of metabolic syndrome (McEvoy et al., 2005; Birkenaes et al., 2007) and an increased mortality rate (Laursen et al., 2007) were observed in schizophrenic patients. The risk of weight gain is variable among SGA. Olanzapine and clozapine are associated with the highest risk of weight gain, followed by chloropromzaine, resperidone, and quetiapine (Lett et al., 2012). Ziprasidone belongs to the group with the lowest risk of weight gain, and it has even shown to reduce weight gain by increasing 
resting energy expenditure without decreasing food intake (Park et al., 2012). The rank order of SGA for inducing weight gain is consistent with that of their metabolic side effects (Newcomer, 2005, 2007), supporting the idea that drug's risk for adverse metabolic changes are strongly associated with its potency for increasing adiposity. Although differential binding affinity of individual SGA to histamine, serotonin, $\alpha$-adrenergic receptors (Kroeze et al., 2003; Matsui-Sakata et al., 2005; Deng et al., 2010) or PKC- $\beta$ activation (Pavan et al., 2010) has been suggested as possible mechanisms, the biochemical and pharmacological bases of SGA-induced weight gain are mostly unclear.

Brown adipose tissue (BAT) serves a specialized function in adaptive thermogenesis and plays an opposite role to that of white adipose tissue by burning metabolic substrates instead of storing energy in the form of triglycerides. Therefore, BAT has long been accepted as an important metabolic organ in small mammals such as mice or rats, but was previously considered to have little physiological relevance in humans beyond early childhood. However, several lines of evidence using ${ }^{18} \mathrm{~F}$-fluorodeoxyglucose positron emission tomography clearly confirmed the existence of active BAT in humans (Nedergaard et al., 2007; Lichtenbelt et al., 2009). Moreover, recent studies also suggested a possible role of BAT in human energy metabolism. BAT activation is either stimulated by cold, insulin, and catecholamines (Orava et al., 2011; Wang et al., 2011) or downregulated by central obesity and bariatric surgery (Wang et al., 2011; Vijgen et al., 2012). Promoting brown adipocyte differentiation leads to an increase in energy expenditure and a reduction in weight gain (Tseng et al., 2008), whereas reduced brown adipocyte differentiation is associated with obesity and insulin resistance in humans (Yang et al., 2003). To the best of our knowledge, only two reports have suggested a possible involvement of BAT in psychotropic-induced obesity. Lithium, which is primary therapy for bipolar disorder and known to induce obesity in humans, inhibited the differentiation of mouse brown adipocytes (Rodríguez de la Concepción et al., 2005). In the sole physiological study, clozapine reversed the thermogensis of brown adipose tissue in rabbits (Blessing et al., 2006). Taken together, these findings suggest that SGA are very likely to induce weight gain by the inhibition of brown adepogenesis. Therefore, we examined the relevance between SGA and weight gain by comparing the effect of clozapine, quetiapine, and ziprasidone on the differentiation of mouse brown preadipocytes. In this study, we provide for the first time biochemical and molecular biological evidence showing that SGA may induce weight gain and metabolic disturbances by inhibiting brown adipocyte differentiation.

\section{Results and Discussion}

\section{Rationale for the selection of drugs and their concentration}

To reveal the possible involvement of BAT in clozapine- or quetiapine-induced weight gain, we examined the effect of clozapine, quetiapine, and ziprasidone on the brown adipocyte differentiation. For a more rational and objective comparison, we selected the concentration of each drug at which they exert similar clinical efficacies based on the recent therapeutic reference ranges (TRR) recommended by the Arbeitsgemeinschaft fur Neuropshychopharmakologie und Pharmakopsychiatrie (AGNP) (Hiemke et al., 2011). In addition, since a previous report showed that clozapine did not increase intracellular triglyceride content during adipogenic differentiation of human adipose-derived stem cells at $30 \mu \mathrm{M}$, which was 16 -fold higher than the upper limit concentration of TRR (Sertié et al., 2011), we evaluated the effect of the drugs at the concentrations that were approximately 20 -fold higher than the upper limit of TRR, i.e. clozapine ( 40 $\mu \mathrm{M})$, quetiapine $(30 \mu \mathrm{M})$, and ziprasidone $(10 \mu \mathrm{M})$.

\section{Effects of drugs on the adipogenic differentiation of brown preadipocytes}

To disclose the involvement of BAT in three SGA-induced weight gains, the effect of the drugs on the differentiation of the brown preadipocyte cell line was examined. We induced adipogenic differentiation for 8 days in the presence of clozapine $(40 \mu \mathrm{M})$, quetiapine $(30 \mu \mathrm{M})$, and ziprasidone (10 $\mu \mathrm{M})$, and examined intracellular accumulation of triglyceride by Oil Red-O staining. As shown in Figure 1 , brown adipocyte differentiation was suppressed almost completely and partly by clozapine and quetiapine, respectively. However, ziprasidone did not show any effect on the differentiation of brown preadipocytes. When we examined the effect on cell viability, clozapine (1.25-40 $\mu \mathrm{M})$, quetiapine (10-60 $\mu \mathrm{M})$, and ziprasidone (2-12 $\mu \mathrm{M})$ did not demonstrate any cytotoxicity during the adipogenic differentiation period (Supplemental Data Figure S1). These results imply that the inhibitory potency of individual drug on brown adipogenesis may be proportionate to its risk for the induction of weight gain and metabolic disturbances. It is noteworthy that clozapine inhibited the differentiation of brown preadipocytes in our results while it did not induce any changes in white preadipocytes (Hu et al., 2010; Sertié et al., 


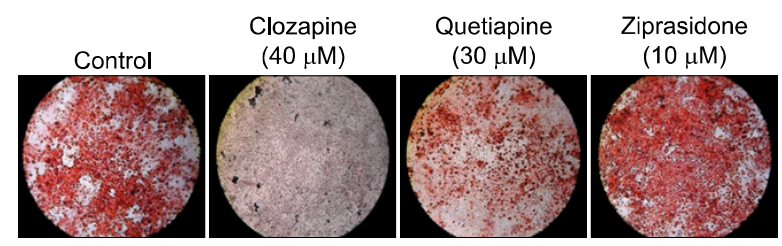

Figure 1. Effect of clozapine, quetiapine and ziprasidone on brown adipocyte differentiation. Brown preadipocytes were differentiated with the induction media in the presence of clozapine $(40 \mu \mathrm{M})$, quetiapine (30 $\mu \mathrm{M})$, and ziprasidone $(10 \mu \mathrm{M})$ or control (0.1\% DMSO). At day 8 , fully differentiated cells were stained with Oil Red-O and photographed by phase-contrast microscopy. Representative data from three independent experiments are shown (Original magnification, $100 \times$ ).

2011). In addition, olanzapine and resperidone, which showed a similar weight gain risk to clozapine and quetiapine, respectively, also induced adipogenesis in 3T3-L1 cells (Yang et al., 2007; Hu et al., 2010). These findings strongly suggest the differential regulatory role of SGA in the differentiation of white and brown preadipocytes. Ziprasidone $(0.2 \mu \mathrm{M})$ and clozapine $(40 \mu \mathrm{M})$ were shown to be highly toxic during adipogenic differentiation from adipose-derived stem cells (Sertié et al., 2011), but in our results, the viability of brown preadipocytes was absolutely not affected even at a much higher (ziprasidone, $10 \mu \mathrm{M}$ ) or at the same (clozapine, $40 \mu \mathrm{M}$ ) concentrations (Supplemental Data Figure S1). Although there are significant differences between these two cell types, these findings suggest the possibility that brown preadipocytes may be more resistant to the cytotoxic activity of SGA than white preadipocytes. In accordance with this point of view, Nisoli et al. (2006) reported that white adipocytes are less prone to apoptotic stimuli than brown adipocytes. Further experiments are needed to investigate the differential responses of white and brown (pre)adipocytes to SGA.

\section{Effects of drugs on the expression of brown adipocyte markers}

Despite the difference in the developmental origin and physiological function of brown and white adipocytes, both cell types share a very similar transcriptional cascade. Indeed, PPAR $\gamma$ is absolutely necessary for both white and brown fat development (Kajimura et al., 2010). Moreover, C/EBP $\beta$ induces PGC-1 $\alpha$ (Wang et al., 2008), and has been recently suggested as a critical transcription factor for the initiation of brown fat formation (Kajimura et al., 2009). However, the development of the specific characteristics of brown adipocytes requires the expression of additional transcriptional regulators. PRDM16, a zinc finger protein, activates PPAR $\gamma 2$, forms a transcriptional complex with $\mathrm{C} / \mathrm{EBP} \beta$
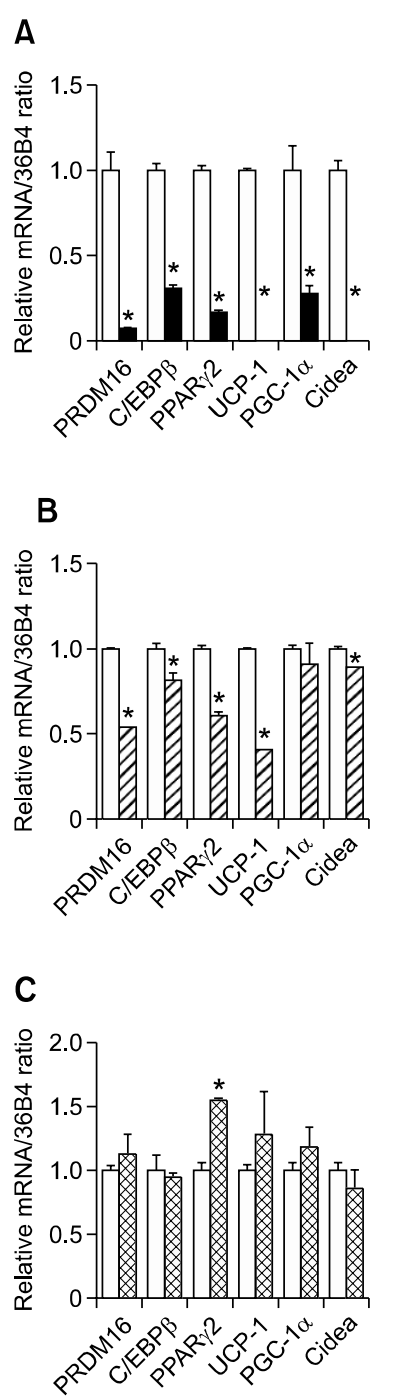

Figure 2. Effect of clozapine, quetiapine and ziprasidone on the expression of brown adipocyte-specific markers. Brown preadipocytes were differentiated with the induction media in the presence of $(A)$ clozapine $(\square, 40 \mu \mathrm{M}),(\mathrm{B})$ quetiapine $(\mathbb{Z}, 30 \mu \mathrm{M})$, and $(\mathrm{C})$ ziprasidone ( 10 $\mu \mathrm{M})$ or DMSO $(\square, 0.1 \%)$. At day 8 after the induction, total RNA was isolated, and the expressions of brown adipocyte markers such as PRDM16, C/EBP $\beta$, PPAR $\gamma 2$, UCP-1, PGC-1 $\alpha$, and Cidea were determined by qRT-PCR. Relative mRNA level of each gene was normalized to the level of 36B4. The data shown are representative of three independent experiments performed in triplicate. Data are mean \pm SEM. ${ }^{*} P<0.05$.

(Kajimura et al., 2009), and finally enhances brown adipogenesis by the induction of brown fat-selective markers such as PGC-1 $\alpha$, UCP-1, and Cidea (Kajimura et al., 2009). To provide molecular evidence for our results showing SGA-induced inhibition of brown adipogenesis (Figure 1), we examined the effect of SGA on the mRNA expression of PRDM16, C/EBP $\beta, P P A R \gamma 2, U C P-1, P G C-1 \alpha$, and Cidea at 8 days after the induction (Figure 2) or during the 

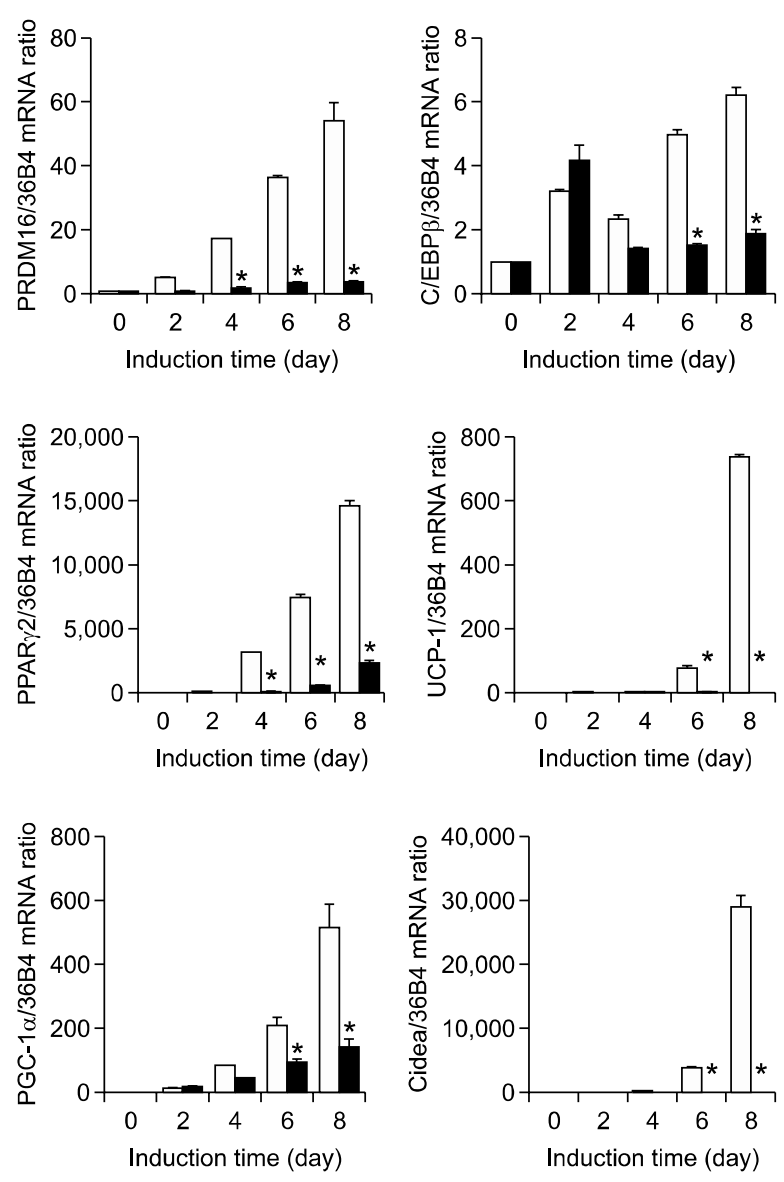

Figure 3. Time-dependent effect of clozapine on the expression of brown adipocyte markers. Brown preadipocytes were differentiated for 8 days with the induction media in the presence of clozapine $(\boldsymbol{\square}, 40 \mu \mathrm{M})$ or DMSO $(\square, 0.1 \%)$. Total RNA was isolated from the cultures at the indicated times, and the expression of brown adipocyte markers such as PRDM16, C/EBP $\beta$, PPAR $\gamma 2$, UCP-1, PGC-1 $\alpha$, and Cidea were determined by qRT-PCR. Relative mRNA level of each gene was normalized to the level of 36B4. The data shown are representative of three independent experiments performed in triplicate. Data are mean \pm SEM. ${ }^{*} P<0.05$.

differentiation of brown preadipocytes (Figure 3, Supplemental Data Figure S2). The results revealed that clozapine significantly inhibited the expression of all genes tested $(P<0.05)$, and particularly PRDM16, UCP-1 and Cidea were almost disappeared by day $8(P<0.05)$ (Figure $2 A)$. Inhibitory effect of clozapine was time-dependent, and this was apparent from day 4 for PRDM16 and PPAR 2 (Figure 3). Quetiapine also down-regulated the expression of PRDM16, PPAR 2 2, UCP-1, and Cidea at day 8 after the induction $(P<0.05)$, but the intensity was much weaker than clozapine (Figure 2B). Inhibitory effect of quetiapine was also not consistent as that of clozapine, for example, $C E B P \beta$ was transiently inhibited only at days 4 and 6 (Figure 2C, Supplemental Data Figure S2A). In contrast to clozapine and quetiapine, ziprasidone showed inhibitory activity only in the early stage of the differentiation, and PPAR $\gamma 2$ expression was significantly increased at days 6 and $8(P<0.05)$ (Supplemental Data Figure S2B). These findings clearly correspond with the results from Oil Red-O staining (Figure 1), and strongly support our hypothesis that the inhibition of brown adipogenesis may be one of the mechanisms for SGA-induced weight gain. Among the genes tested in our stuy, transcriptional regulation of PRDM16 by clozapine and quetiapine is remarkable since they are considered as master regulators for brown adipogenesis. Brown adipogenesis from white preadipocytes or myoblasts was successfully induced by the ectopic expression of PRDM16 (Seale et al., 2007), and BAT from PRDM $16^{-/-}$mice exhibited an abnormal morphology and reduced expression of brown fat markers (Seale et al., 2008). Recently, association of PRDM16 with metabolic syndrome was also suggested (Zhang et al., 2012). Considering the rapid rise in importance of PRDM16 in energy homeostasis, finding the signaling molecules that control the expression of PRDM16 are warranted, and in this respect, it is valuable to further identify a missing link between PRDM16 and clozapine or quetiapine in brown adipocytes.

\section{Effects of drugs on the expression of genes for lipogenesis and adipokines}

Transcriptional regulators involved in brown adipogenesis, such as PPAR $\gamma 2$, PRDM16 and C/EBP $\beta$, cooperatively promote adipogenesis. Therefore, it is likely predicted that clozapine or quetiapine decreases the expression of lipogenic genes. When the transcriptions of typical lipogenic genes were examined at 8 days after the adipogenic induction of brown preadipocytes, clozapine was shown to significantly decrease the transcription of all genes except for FAS, and the inhibitory potency was particularly higher in GLUT4, aP2 and CD36 $(P<$ 0.05 ) (Figure 4A). In comparison, quetiapine and ziprasidone did not affect the lipogenic gene expression (Figures 4B and $4 \mathrm{C}$ ). We also examined the expression of adipokines such as resistin, leptin and adiponectin because their expressions were increased in differentiated brown adipocytes in previous studies (Kraus et al., 2002; Viengchareun et al., 2002). Clozapine significantly inhibited mRNA expression of resistin, leptin and adiponectin, and among them leptin showed the most sensitive reaction to the inhibitory activity of clozapine $(P<$ 0.05 ) (Figure 4A). Quetiapine also inhibited resistin and leptin levels but with much weaker potency than clozapine (Figure 4B). However, no inhibitory activity 
A

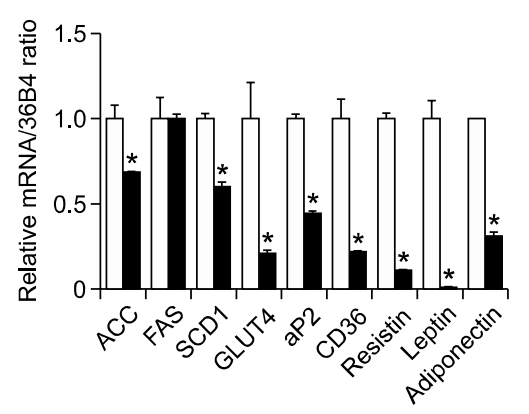

B

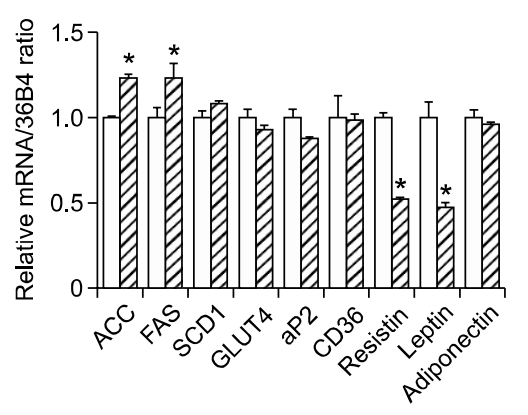

C

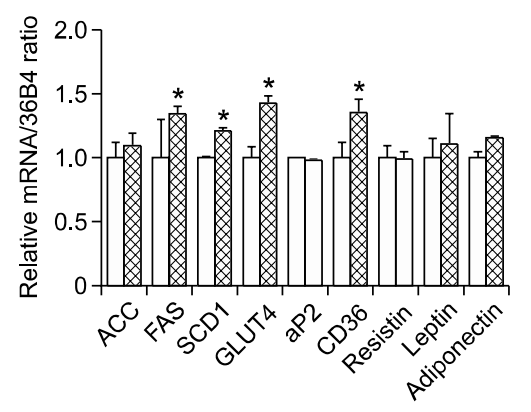

Figure 4. Effect of clozapine, quetiapine and ziprasidone on the expression of lipogenic genes and adipokines. Brown preadipocytes were differentiated with the induction media in the presence of $(A)$ clozapine $(\boldsymbol{\square}, 40 \mu \mathrm{M})$, (B) quetiapine ( $\mathbb{Z}, 30 \mu \mathrm{M})$, and (C) ziprasidone ( 10 $\mu \mathrm{M})$ or DMSO $(\square, 0.1 \%)$. At day 8 after the induction, total RNA was isolated from the cultures, and the expressions of lipogenic genes (ACC, FAS, SCD1, aP2, CD36 and GLUT4), and adipokines (resistin, leptin and adiponectin) were determined by qRT-PCR. Relative mRNA level of each gene was normalized to the level of 36B4. The data shown are representative of three independent experiments performed in triplicate. Data are mean \pm SEM. ${ }^{*} P<0.05$.

of ziprasidone was observed (Figure 4C). In our results, leptin was down-regulated by clozapine and quetiapine in proportionate to their potencies for weight gain. Leptin is a well-known factor for reduction of body fat by decreasing food intake and increasing energy expenditure, and its genetic variation is associated with clozapine-induced weight gain (Brandl et al., 2012). In this context along with our findings strongly suggest that leptin is a plausible candidate for SGA-induced weight gain. This brought us to our next question of how clozapine or quetiapine can down-regulate leptin expression in brown adipocytes. Two recent reports left promising clues to this question. Insulin is an important regulator for leptin synthesis and secretion (Saladin et al., 1995), and recently, Panariello et al. (2012) clearly demonstrated that clozapine impairs insulin signaling both in vitro and in vivo. Moreover, UCP-1 increased leptin activity (Okamatsu-Ogura et al., 2011), suggesting the possibility that, in addition to the suppression of its expression, clozapine may down-regulate the activity of leptin by inhibiting the UCP-1 expression (Figures 2 and 3 ). Taken together, it is reasonable to assume that clozapine may contribute to weight gain by the inhibition of synthesis and activity of leptin through disturbing insulin signaling and UCP-1 expression. However, in contrast to these observations, many conflicting results were reported. For example, clozapine did not change the expression of leptin in vitro (Hauner et al., 2003) or even elevated the serum level in patients with schizophrenia treated with clozapine (Monteleone et al., 2002). Further studies are needed to clarify the role of SGA in the regulation adipokines in brown adipocytes.

\section{Dose-dependent effect of clozapine on the expression of brown adipocyte markers}

In spite of the very distinct effects of clozapine, quetiapine and ziprasidone on brown adipocyte differentiation, the concentrations used in our study seems to be unphysiological because they are 20 -fold higher than the plasma concentrations achieved in the course of routine treatment in practice. To confer more clinical implications on our results, we examined whether clozapine, at a lower concentration range, still showed anti-adipogenic activity by measuring the expression of brown fat-specific markers. As shown in Figure 5A, the inhibitory activity of clozapine on the mRNA expression of $P R D M 16, C / E B P \beta$, and Cidea was observed from $20 \mu \mathrm{M}(P<0.05)$, and at this concentration, PPAR $\gamma 2$ and PGC-1 $\alpha$ were also inhibited at the protein level (Figure 5B). Moreover, UCP-1, the hallmark of brown fat, showed the highest sensitivity to clozapine, started to decrease from $10 \mu \mathrm{M}$, which is a concentration only 5 -fold higher than the therapeutic reference range, at both mRNA and protein levels $(P<0.05)$ (Figure 5$)$. Quetiapine also inhibited PRDM16, C/EBP $\beta, P P A R \gamma 2$, and UCP-1 expressions in a dose-dependent manner, but only at concentrations higher than 30 $\mu \mathrm{M}$ (Supplemental Data Figures S3A and S3B). Additionally, ziprasidone did not affect, or even 

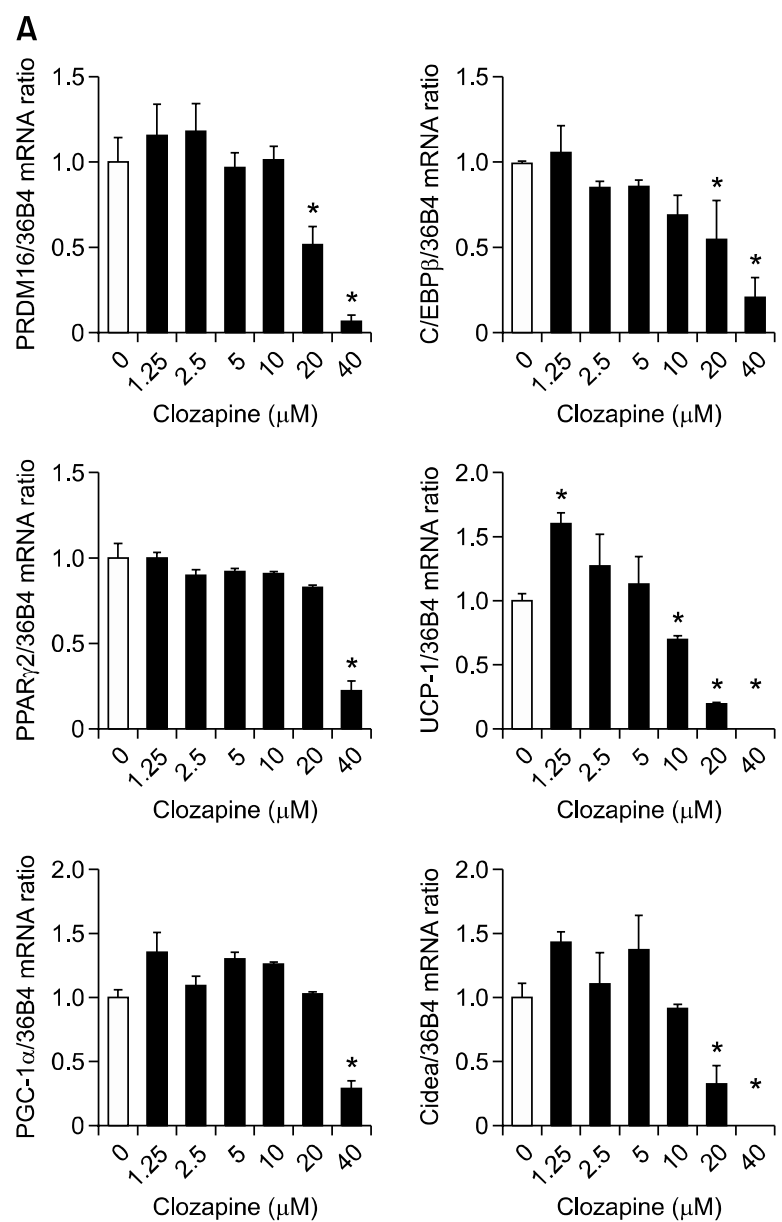

B

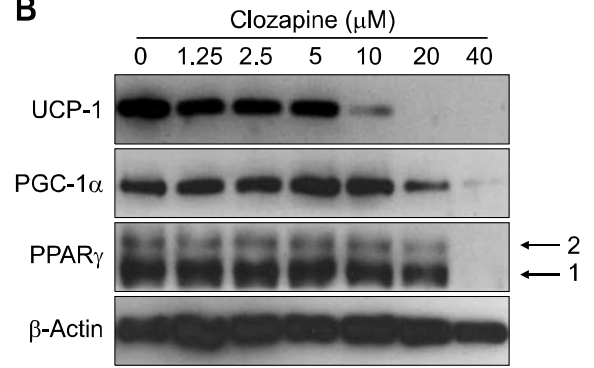

Figure 5. Dose-dependent effect of clozapine on the expression of brown adipocyte markers. Brown preadipocytes were differentiated for 8 days in induction media in the presence of indicated concentration of clozapine ( $\mathbf{\square}$ ) or $0.1 \%$ DMSO ( $\square$ ). (A) mRNA expression. Total RNA was isolated from the cultures, and the expressions of brown adipocyte markers PRDM16, C/EBP $\beta$, PPAR $\gamma 2$, UCP-1, PGC-1 $\alpha$, and Cidea were determined by qRT-PCR. Relative mRNA level of each gene was normalized to the levels of 36B4. Data are mean \pm SEM. ${ }^{*} P<0.05$. (B) Protein expression. Protein was prepared from the cultures at day 8 , and the expression levels of UCP-1, PGC-1 $\alpha$ and PPAR 2 were determined by immunoblot analysis. Bata-actin was used as a loading control. The data shown are representative of three independent experiments performed in triplicate. increase the expression of PPAR $\gamma 2$ at a higher concentration $(12 \mu \mathrm{M})$ (Supplemental Data Figures S4A and S4B). Based on these findings which clearly showed the inhibitory activity of clozapine at a concentration much closer to the therapeutic level, it is not unlikely that our in vitro findings of clozapine may also occur in BAT in vivo. Multiple lines of previous observations also support this possibility. There is a considerable inter- and intra-individual variability in the pharmacokinetic properties in patients receiving clozapine (Cheng et al., 1988). For example, the plasma level of clozapine is higher in women than men and increases with age (Lane et al., 1999). Some drugs inhibiting CYP1A2, the main enzyme catalyzing clozapine, such as ciprofloxacin (Markowitz et al., 1997) and fluvoxamine (Shader and Greenblatt, 1998) were able to increase serum clozapine concentration by up to 10 -fold. More importantly, the adipose/plasma concentration ratio of highly lipophilic drugs like clozapine was in the range of $2-5$ (Bickel et al., 1983). Taking these findings and our results into consideration, we cannot exclude the possibility that clozapine concentration in adipose tissue by chance reaches to the range used in our experiments.

In summary, consistent findings from our experiments comparing the effect of clozapine, quetiapine and ziprasidone on brown adipogenesis strongly suggest that SGA inhibits brown adipocyte differentiation with the potency proportional to their propensities for weight gain. These effects in brown adipogenesis may propose a possible mechanism to explain obesity which is frequently observed in patients treated with clozapine and quetiapine. Further research is necessary to weigh the pathophysiological significance of our in vitro findings in humans.

\section{Methods}

\section{Materials}

Dulbecco's modified Eagle's medium (DMEM) and fetal bovine serum (FBS) were purchased from Invitrogen (Carlsbad, CA). Insulin, 3-isobutyl-1-methylxanthine (IBMX), dexamethasone, indomethacin, 3,3',5-triodo-L-thyronine (liothyronine, T3), Oil Red-O, clozapine and ziprasidone were obtained from Sigma-Aldrich (St. Louis, MO). Quetiapine was obtained from Ildong Pharmaceutical Co. (Seoul, Korea). Cell Counting Kit-8 (CCK-8) was purchased from Dojindo Laboratories (Kumamoto, Japan).

\section{Induction of brown adipocyte differentiation}

Brown preadipocyte cell line was kindly gifted from $\mathrm{Dr}$. Ge (NIDDK, NIH, Bethesda, MD), and cells were grown at $37^{\circ} \mathrm{C}$ in a humidified $5 \% \mathrm{CO}_{2}$ incubator (Cho et al., 2009). 
Differentiation of brown preadipocytes was carried out as described previously (Wang et al., 2011). Briefly, cells were maintained in DMEM containing $10 \%$ FBS before initiating differentiation, and grown to confluence in the differentiation medium (DMEM containing 10\% FBS, $0.1 \mu \mathrm{M}$ insulin, and $1 \mathrm{nM} \mathrm{T3)}$. Four days after the induction of confluence (day 0 ), cells were stimulated for 2 days with the induction medium (differentiation medium containing 0.5 $\mathrm{mM}$ IBMX, $2 \mu \mathrm{g} / \mathrm{ml}$ dexamethasone, and $0.125 \mathrm{mM}$ indomethacin), and then the cultures were subjected to the differentiation medium, and changed every 2 days. Full differentiation was achieved at day 8 .

\section{Cell viability test}

Cells were plated into 12-well cell culture plates at a density of $3.6 \times 10^{4}$ cells per well, and brown adipocyte differentiation was induced in the presence of the indicated concentration of drugs (clozapine, quetiapine and ziprasidone) or $0.1 \%$ DMSO for 8 days. The differentiated cells were tested for cell viability using CCK-8 according to the manufacturer's instructions. Briefly, $100 \mu \mathrm{l}$ of CCK-8 solution was added to each culture and then incubated at $37^{\circ} \mathrm{C}$ for $4 \mathrm{~h}$. The cytotoxicity was evaluated by measuring the absorbance at $450 \mathrm{~nm}$ on a microplate reader (PerkinEImer, Waltham, MA).

\section{Oil Red-O staining}

At the indicated times after the induction, cells were washed two times with phosphate-buffered saline (PBS, pH 7.4), and fixed with $10 \%$ formalin for 20 min. After washing with distilled water (DW) and 60\% isopropanol twice, cells were incubated with Oil Red-O working solution $(0.3 \%$ Oil Red-O, $60 \%$ isopropanol). After $30 \mathrm{~min}$. cells were thoroughly washed with $60 \%$ isopropanol and DW to remove unbound dye. Stained cells were dried on air and analyzed by microscopic examination (Leica DMIL microscope, Leica, Wetzlar, Germany).

\section{Quantitative real-time PCR}

Total RNA was extracted from the cultures using Trizol Reagent (Invitrogen), and cDNA was synthesized from 0.5 $\mu \mathrm{g}$ of total RNA using PrimeScriptTM RT reagent Kit (Takara, Shiga, Japan). The quantitative real-time PCR (qRT-PCR) analysis was performed on at least three independent RNA samples using ABI 7300 thermal cycler (Applied Biosystems, Foster City, CA) with SYBR Green Q-PCR Master Mix (Takara). The relative amount of mRNAs was calculated using the $\Delta \Delta \mathrm{Ct}$ method with the $36 \mathrm{~B} 4$ mRNA as an internal control. The used primer sequences for qRT-PCR are described at Supplemental Data Table S1.

\section{Immunoblot analysis}

Differentiated brown adipocytes were washed with PBS twice, and then harvested by scraping. After centrifugation at $800 \mathrm{~g}$ for $1 \mathrm{~min}$, the pellets were lysed in RIPA buffer (Cell Signaling, Beverly, MA) containing protease inhibitors, and then incubated on ice for $30 \mathrm{~min}$. All samples were then centrifuged at $17,000 \mathrm{~g}$ at $4^{\circ} \mathrm{C}$ for $30 \mathrm{~min}$ and the supernatant was saved at $-80^{\circ} \mathrm{C}$. Thirty micrograms of total protein were separated by $12 \%$ SDS-PAGE and transferred onto a nitrocellulose membrane (Schleicher \& Schell, Dassel, Germany). The membranes were blocked with $5 \%$ non-fat milk and incubated overnight at $4{ }^{\circ} \mathrm{C}$ with the antisera against $\beta$-actin (1:1,000, Sigma-Aldrich), UCP-1 (1:200, Abcam, Boston, MA), PGC-1 $\alpha$ and PPAR 2 (1:250, Santa Cruz). Antibody binding was detected using horseradish peroxidase-conjugated anti-rabbit or anti-mouse IgG (1:2,000; Sigma-Aldrich) and the immunoreactive bands were visualized with ECL method (Amersham Pharmacia Biotech, Little Chalfont, UK).

\section{Statistical analysis}

All values are expressed as the means \pm SEM from at least three independent experiments. All statistical calculations were performed using GraphPad Prism 5.03 software (GraphPad Software Inc., San Diego, CA). One- or two-way ANOVA followed by Turkey's Multiple Comparison Test was used to compare means. A probability $(P)$ value less than 0.05 was considered to be significant.

\section{Supplemental data}

Supplemental data include four figures and a table and can be found with this article online at http://e-emm.or.kr/article/ article_files/SP-44-9-04.pdf.

\section{Acknowledgements}

This research was supported by a grant (10172KFDA993) from Korea Food \& Drug Administration in 2012, and by the Catholic Medical Center Research Foundation made in the program year of 2009 .

\section{References}

Bickel MH, Graber BE, Moor M. Distribution of chlorpromazine and imipramine in adipose and other tissues of rats. Life Sci 1983;33:2025-31

Birkenaes $A B$, Opjordsmoen S, Brunborg C, Engh JA, Jonsdottir H, Ringen PA, Simonsen C, Vaskinn A, Birkeland KI, Friis S, Sundet K, Andreassen OA. The level of cardiovascular risk factors in bipolar disorder equals that of schizophrenia: a comparative study. J Clin Psychiatry 2007;68:917-23

Blessing WW, Zilm A, Ootsuka Y. Clozapine reverses increased brown adipose tissue thermogenesis induced by 3,4-methylenedioxymethamphetamine and by cold exposure in conscious rats. Neuroscience 2006;141:2067-73

Brandl EJ, Frydrychowicz C, Tiwari AK, Lett TA, Kitzrow W, Büttner S, Ehrlich S, Meltzer HY, Lieberman JA, Kennedy JL, Müller DJ, Puls I. Association study of polymorphisms in leptin and leptin receptor genes with antipsychotic-induced body weight gain. Prog Neuropsychopharmacol Biol Psychiatry 2012;38:134-41

Cheng YF, Lundberg T, Bondesson U, Lindström L, 
Gabrielsson J. Clinical pharmacokinetics of clozapine in chronic schizophrenic patients. Eur J Clin Pharmacol 1988; $34: 445-9$

Cho YW, Hong S, Jin Q, Wang L, Lee JE, Gavrilova O, Ge $\mathrm{K}$. Histone methylation regulator PTIP is required for PPARgamma and C/EBPalpha expression and adipogenesis. Cell Metab 2009;10:27-39

Deng C, Weston-Green K, Huang XF. The role of histaminergic $\mathrm{H} 1$ and $\mathrm{H} 3$ receptors in food intake: a mechanism for atypical antipsychotic-induced weight gain? Prog Neuropsychopharmacol Biol Psychiatry 2010;34:1-4

Hauner H, Röhrig K, Hebebrand J, Skurk T. No evidence for a direct effect of clozapine on fat-cell formation and production of leptin and other fat-cell-derived factors. Mol Psychiatry 2003;8:258-9

Hiemke C, Baumann P, Bergemann N, Conca A, Dietmaier O, Egberts K, Fric M, Gerlach M, Greiner C, Gründer G, Haen $E$, Havemann-Reinecke $U$, Jaquenoud Sirot E, Kirchherr H, Laux G, Lutz UC, Messer T, Müller MJ, Pfuhlmann B, Rambeck B, Riederer P, Schoppek B, Stingl J, Uhr M, Ulrich $\mathrm{S}$, Waschgler R, Zernig G. AGNP consensus guidelines for therapeutic drug monitoring in psychiatry: update 2011. Pharmacopsychiatry 2011;44:195-235

Hu Y, Kutscher E, Davies GE. Berberine inhibits SREBP-1related clozapine and risperidone induced adipogenesis in 3T3-L1 cells. Phytother Res 2010;24:1831-8

Kajimura S, Seale P, Kubota K, Lunsford E, Frangioni JV, Gygi SP, Spiegelman BM. Initiation of myoblast to brown fat switch by a PRDM16-C/EBP-beta transcriptional complex. Nature 2009;460:1154-8

Kajimura S, Seale P, Spiegelman BM. Transcriptional control of brown fat development. Cell Metab 2010;11:257-62

Kraus D, Fasshauer M, Ott V, Meier B, Jost M, Klein HH, Klein J. Leptin secretion and negative autocrine crosstalk with insulin in brown adipocytes. J Endocrinol 2002;175:185-91

Kroeze WK, Hufeisen SJ, Popadak BA, Renock SM, Steinberg S, Ernsberger P, Jayathilake K, Meltzer HY, Roth BL. H1-histamine receptor affinity predicts short-term weight gain for typical and atypical antipsychotic drugs. Neuropsychopharmacology 2003;28:519-26

Lane HY, Chang YC, Chang WH, Lin SK, Tseng YT, Jann MW. Effects of gender and age on plasma levels of clozapine and its metabolites: analyzed by critical statistics. J Clin Psychiatry 1999;60:36-40

Laursen TM, Munk-Olsen T, Nordentoft M, Mortensen PB. Increased mortality among patients admitted with major psychiatric disorders: a register-based study comparing mortality in unipolar depressive disorder, bipolar affective disorder, schizoaffective disorder, and schizophrenia. J Clin Psychiatry 2007;68:899-907

Lett TA, Wallace TJ, Chowdhury NI, Tiwari AK, Kennedy JL, Müller DJ. Pharmacogenetics of antipsychotic-induced weight gain: review and clinical implications. Mol Psychiatry 2012;17:242-66

Markowitz JS, Gill HS, DeVane CL, Mintzer JE. Fluoroquinolone inhibition of clozapine metabolism. Am J Psychiatry 1997; 153:881
Matsui-Sakata A, Ohtani H, Sawada Y. Receptor occupancybased analysis of the contributions of various receptors to antipsychotics-induced weight gain and diabetes mellitus. Drug Metab Pharmacokinet 2005;20:368-78

McEvoy JP, Meyer JM, Goff DC, Nasrallah HA, Davis SM, Sullivan L, Meltzer HY, Hsiao J, Scott Stroup T, Lieberman JA. Prevalence of the metabolic syndrome in patients with schizophrenia: Baseline results from the Clinical Antipsychotic Trials of Intervention Effectiveness (CATIE) schizophrenia trial and comparison with national estimates from NHANES III. Schizophr Res 2005;80:19-32

Monteleone P, Fabrazzo M, Tortorella A, La Pia S, Maj M. Pronounced early increase in circulating leptin predicts a lower weight gain during clozapine treatment. J Clin Psychopharmacol 2002;22:424-6

Nedergaard J, Bengtsson T, Cannon B. Unexpected evidence for active brown adipose tissue in adult humans. Am J Physiol Endocrinol Metab 2007;293:E444-52

Newcomer JW. Second-generation (atypical) antipsychotics and metabolic effects: a comprehensive literature review. CNS Drugs 2005;19(Suppl 1):1-93

Newcomer JW. Metabolic considerations in the use of antipsychotic medications: a review of recent evidence. $J$ Clin Psychiatry 2007;68(Suppl 1):20-7

Nisoli E, Cardile A, Bulbarelli A, Tedesco L, Bracale R, Cozzi V, Morroni M, Cinti S, Valerio A, Carruba MO. White adipocytes are less prone to apoptotic stimuli than brown adipocytes in rodent. Cell Death Differ 2006;13:2154-6

Okamatsu-Ogura Y, Nio-Kobayashi J, Iwanaga T, Terao A, Kimura K, Saito M. Possible involvement of uncoupling protein 1 in appetite control by leptin. Exp Biol Med (Maywood) 2011;236:1274-81

Orava J, Nuutila P, Lidell ME, Oikonen V, Noponen T, Viljanen T, Scheinin M, Taittonen M, Niemi T, Enerbäck S, Virtanen KA. Different metabolic responses of human brown adipose tissue to activation by cold and insulin. Cell Metab 2011;14: 272-9

Panariello F, Perruolo G, Cassese A, Giacco F, Botta G, Barbagallo AP, Muscettola G, Beguinot F, Formisano P, de Bartolomeis A. Clozapine impairs insulin action by up-regulating Akt phosphorylation and Ped/Pea-15 protein abundance. J Cell Physiol 2012;227:1485-92

Park S, Kim MS, Namkoong C, Park MH, Hong JP. The effect of ziprasidone on body weight and energy expenditure in female rats. Metabolism 2012;61:787-93

Pavan C, Vindigni V, Michelotto L, Rimessi A, Abatangelo G, Cortivo R, Pinton P, Zavan B. Weight gain related to treatment with atypical antipsychotics is due to activation of PKC- $\beta$. Pharmacogenomics J 2010;10:408-17

Rodríguez de la Concepción ML, Yubero P, Iglesias R, Giralt $M$, Villarroya F. Lithium inhibits brown adipocyte differentiation. FEBS Lett 2005;579:1670-4

Saladin R, De Vos P, Guerre-Millo M, Leturque A, Girard J, Staels B, Auwerx J. Transient increase in obese gene expression after food intake or insulin administration. Nature 1995;377:527-9 
Seale P, Kajimura S, Yang W, Chin S, Rohas LM, Uldry M, Tavernier G, Langin D, Spiegelman BM. Transcriptional control of brown fat determination by PRDM16. Cell Metab 2007;6:38-54

Seale P, Bjork B, Yang W, Kajimura S, Chin S, Kuang S, Scimè A, Devarakonda S, Conroe HM, Erdjument-Bromage $\mathrm{H}$, Tempst P, Rudnicki MA, Beier DR, Spiegelman BM. PRDM16 controls a brown fat/skeletal muscle switch. Nature 2008;454:961-7

Sertié AL, Suzuki AM, Sertié RA, Andreotti S, Lima FB, Passos-Bueno MR, Gattaz WF. Effects of antipsychotics with different weight gain liabilities on human in vitro models of adipose tissue differentiation and metabolism. Prog Neuropsychopharmacol Biol Psychiatry 2011;35:1884-90

Shader RI, Greenblatt DJ. Clozapine and fluvoxamine, a curious complexity. J Clin Psychopharmacol 1998;18:101-2

Tseng YH, Kokkotou E, Schulz TJ, Huang TL, Winnay JN, Taniguchi CM, Tran TT, Suzuki R, Espinoza DO, Yamamoto Y, Ahrens MJ, Dudley AT, Norris AW, Kulkarni RN, Kahn CR. New role of bone morphogenetic protein 7 in brown adipogenesis and energy expenditure. Nature 2008;454: 1000-4

Van Marken Lichtenbelt WD, Vanhommerig JW, Smulders NM, Drossaerts JM, Kemerink GJ, Bouvy ND, Schrauwen P, Teule GJ. Cold-activated brown adipose tissue in healthy men. N Engl J Med 2009;360:1500-8

Viengchareun S, Zennaro MC, Pascual-Le Tallec L, Lombes M. Brown adipocytes are novel sites of expression and regulation of adiponectin and resistin. FEBS Lett 2002;532:
345-50

Vijgen GH, Bouvy ND, Teule GJ, Brans B, Hoeks J, Schrauwen P, van Marken Lichtenbelt WD. Increase in brown adipose tissue activity after weight loss in morbidly obese subjects. J Clin Endocrinol Metab 2012;97:E1229-33

Wang H, Peiris TH, Mowery A, Le Lay J, Gao Y, Greenbaum LE. CCAAT/enhancer binding protein-beta is a transcriptional regulator of peroxisome-proliferator-activated receptorgamma coactivator-1alpha in the regenerating liver. Mol Endocrinol 2008;22:1596-605

Wang Q, Zhang M, Ning G, Gu W, Su T, Xu M, Li B, Wang $W$. Brown adipose tissue in humans is activated by elevated plasma catecholamines levels and is inversely related to central obesity. PLoS One 2011;6:e21006

Yang X, Enerbäck S, Smith U. Reduced expression of FOXC2 and brown adipogenic genes in human subjects with insulin resistance. Obes Res 2003;11:1182-91

Yang LH, Chen TM, Yu ST, Chen YH. Olanzapine induces SREBP-1-related adipogenesis in 3T3-L1 cells. Pharmacol Res 2007;56:202-8

Yang Z, Yin JY, Gong ZC, Huang Q, Chen H, Zhang W, Zhou $H H$, Liu ZQ. Evidence for an effect of clozapine on the regulation of fat-cell derived factors. Clin Chim Acta 2009; 408:98-104

Zhang JH, Li NF, Yan ZT, Zhang de L, Wang HM, Guo YY, Ling $Z$. Association of genetic variations of PRDM16 with metabolic syndrome in a general Xinjiang Uygur population. Endocrine 2012;41:539-41 